\title{
Racial differences in ill defined cancer mortality in the United States and in the District of Columbia
}

\author{
Eugene Schwartz, Vincent Y Kofie, Susan R Sturgeon
}

\begin{abstract}
Study objective-The aim was to examine the epidemiology of unknown primary cancer mortality in the USA during 1979 to 1988 by age, sex, race, year, and geographical area.
\end{abstract}

Design-National (US) and state data were abstracted for deaths due to ill defined cancer (ICD-9 195.0 to 199.1) and all cancers combined (ICD-9 140.0-209.9). Age adjusted mortality rates were calculated using the 1980 USA population as the standard, and standardised rate ratios were derived. National total cancer incidence data were obtained from the surveillance, epidemiology and end results (SEER) program, and age and sex specific relative (black/white) cancer incidence rates were derived and compared to relative (black/white) mortality rates for ill defined cancer. State and regional median family income levels were obtained from the 1980 census and compared to corresponding mortality rates.

Setting-This study used data for the US population, the 50 states, and the District of Columbia.

Measurements and main results-During 1984-1988, ill defined cancers accounted for an average of 34921 deaths each year in the USA (13.7 per 100000 population). The mortality rate due to ill defined cancers is greater among blacks $(19 \cdot 3$ per 100000$)$ than whites (13.2 per 100000$)(R R=1.5)$ and has not declined since 1979. There is considerable geographical variation in the ill defined cancer mortality rate. Thus among blacks the highest rates were clustered in the central states (23 per 100000$)$ and the lowest rates were seen in the mountain and western states (17 per 100000$)$. The District of Columbia had the highest overall rate $(21 \cdot 7$ per $100000)$ when compared to all other states. The black/white relative mortality rate due to ill defined cancer was consistently greater than the black/white relative incidence of all cancers.

Conclusions-IIl defined cancer mortality is the fourth leading site of cancer mortality in the USA, and accounts for $\mathbf{7 \cdot 4 \%}$ of cancer deaths annually. The large proportion of ill defined cancer deaths may have biased the accuracy of national and local cancer incidence and mortality statistics. The higher mortality of ill defined cancer among blacks is not explained by the higher overall cancer incidence among blacks and suggests the influence of socioeconomic or cultural barriers that may result in underutilisation of health services or substandard health care. Ill defined cancer mortality may be a sentinel indicator of deficiencies in the health care delivery system as well as a measure of progress against cancer.

f Epidemiol Community Health 1992; 46: 390-393

Ill defined cancer deaths comprise a group of malignancies for which no primary cancer site is identified. ${ }^{1}$ These cases are also termed carcinomatosis, disseminated cancer (unknown primary site), "cancer-site unspecified", or "cancer-generalised". Cases typically represent a clinically advanced stage lung, breast, pancreatic, prostate, or colorectal cancer that has widely metastasised following delay in diagnosis. ${ }^{2}$ Epidemiological analyses of ill defined cancer mortality are not generally published. We postulated that ill defined cancer mortality differentially affects the United States black population, and that this effect cannot be explained by a higher overall cancer incidence among blacks. Further, in view of the increasing availability of advanced technology for diagnosing cancer, we postulated that the mortality rate for this condition would have declined during the past decade.

Becker and colleagues have reported on the epidemiology of deaths due to all non-malignant ill defined conditions (eg, old age, natural causes, cause unknown) in New Mexico. ${ }^{3}$ Ill defined conditions were a leading category of death among minorities, and the authors suggested that racial disparities in mortality from these conditions reflected inequities in the health care system.

We present a descriptive epidemiological analysis of mortality due to ill defined cancer in the USA and the District of Columbia (DC). DC was chosen for study because it is known to experience the highest cancer death rate when compared to all other states and many other major urban centres. ${ }^{4}$ DC serves as the nation's capital and is home to 638000 residents, $72 \%$ of whom are black. ${ }^{5}$

\section{Methods}

All deaths due to ICD-9 codes 195.0-199.1 (ill defined, unspecified or secondary sites, disseminated cancer, carcinomatosis) and 140-209 (all malignant neoplasms) were obtained from death records maintained by the District of Columbia Division of Research and Statistics for the period 1979 to $1988 .{ }^{1}$ Data were tabulated by year, age, sex, and race. The estimated district population was used to calculate annual mortality rates. ${ }^{6}$ Age adjustment of the rates was performed using the direct method with the 1980 US population as the standard. An identical analysis 
was performed for the nation, each of the 50 states and nine geographical regions using US mortality data. ${ }^{7}$

Estimates of national total cancer incidence rates were obtained from the surveillance, epidemiology and end results (SEER) program for the period 1984 to 1987 . Age and sex specific

Figure 1 Trends in ill defined and unspecified cancer mortality in the USA, 1979-88. Death rate adjusted to the 1980 US population

Table I Age adjusted average cancer mortality rate for ill defined and unspecified cancer (ICD 195-199.1) USA and District of Columbia, 1984-1988

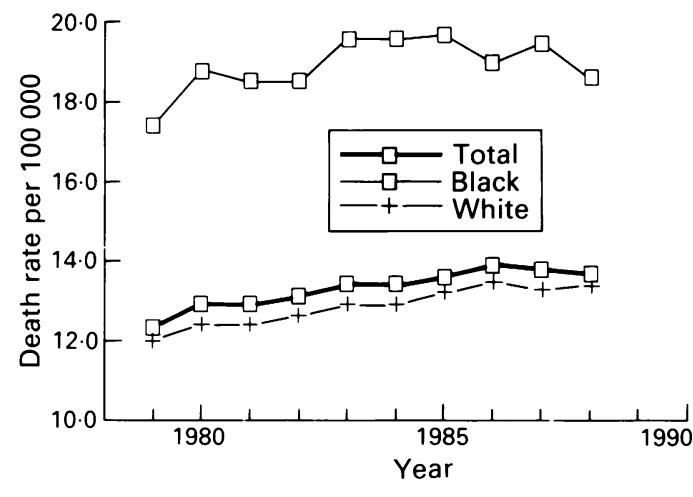

\begin{tabular}{|c|c|c|c|}
\hline Group & $U S A$ & $\begin{array}{l}\text { District of } \\
\text { Columbia }\end{array}$ & $R R^{\mathrm{b}}(D C / U S)$ \\
\hline Total & $13 \cdot 7$ & 21.7 & $1 \cdot 6^{\star}(1 \cdot 5,1 \cdot 7)^{\mathrm{a}}$ \\
\hline $\begin{array}{l}\text { Black } \\
\text { White } \\
\text { B/W ratio }\end{array}$ & $\begin{array}{c}19 \cdot 3 \\
13 \cdot 2 \\
1 \cdot 5^{\star}\end{array}$ & $\begin{array}{l}24 \cdot 8 \\
15 \cdot 3 \\
1 \cdot 6^{\star}(1 \cdot 3,1 \cdot 9)^{c}\end{array}$ & $\begin{array}{l}1 \cdot 3^{\star}(1 \cdot 2,1 \cdot 4) \\
1 \cdot 2(1 \cdot 0,1 \cdot 3) \\
-\end{array}$ \\
\hline $\begin{array}{l}\text { Black males } \\
\text { White males } \\
\text { BM/WM ratio }\end{array}$ & $\begin{array}{c}24 \cdot 9 \\
16 \cdot 4 \\
1.5^{\star}\end{array}$ & $\begin{array}{l}34.9 \\
19 \cdot 5 \\
1 \cdot 8^{\star}(1 \cdot 4,2 \cdot 2)\end{array}$ & $\begin{array}{l}1.4^{\star}(1.2,1.6) \\
1.2(0.9,1.5) \\
-\end{array}$ \\
\hline $\begin{array}{l}\text { Black females } \\
\text { White females } \\
\text { BF/WF }\end{array}$ & $\begin{array}{c}15 \cdot 1 \\
10 \cdot 9 \\
1 \cdot 4^{\star}\end{array}$ & $\begin{array}{l}17 \cdot 9 \\
12 \cdot 5 \\
1 \cdot 4^{\star}(1 \cdot 1,1 \cdot 8)\end{array}$ & $\begin{array}{l}1 \cdot 2^{\star}(1 \cdot 0,1 \cdot 3) \\
1 \cdot 1 \quad(0.9,1 \cdot 4) \\
-\end{array}$ \\
\hline \multicolumn{4}{|c|}{$\begin{array}{l}\text { a Rates are per } 100000 \text { population, age adjusted to the } 1980 \\
\text { population. } \\
{ }_{\mathrm{R}}=\text { relative risk } \\
{ }^{\mathrm{C}} \text { Quantities in parentheses denote the lower and upper } 95 \% \\
\text { confidence intervals of the relative rates. } \\
{ }^{\star} \text { Rate significantly higher at the } \mathrm{p}=0.05 \text { level. }\end{array}$} \\
\hline
\end{tabular}

Table II Percentage of all cancer deaths $s^{\mathrm{a}}$ due to ill defined cancer ${ }^{\mathrm{b}}$ in the USA, by age, race, and sex, 1984-1988

\begin{tabular}{|c|c|c|c|c|c|c|}
\hline \multirow[b]{2}{*}{ Age group (years) } & \multicolumn{3}{|l|}{ Men } & \multicolumn{3}{|c|}{ Women } \\
\hline & Black & White & Ratio & Black & White & Ratio \\
\hline $\begin{array}{l}25-34 \\
35-44 \\
45-54 \\
55-64 \\
65-74 \\
75-84 \\
85+\end{array}$ & $\begin{array}{r}8 \cdot 8 \\
10 \cdot 0 \\
9 \cdot 3 \\
8 \cdot 3 \\
7 \cdot 3 \\
7 \cdot 2 \\
7 \cdot 7\end{array}$ & $\begin{array}{l}6 \cdot 0 \\
7 \cdot 3 \\
7 \cdot 4 \\
7 \cdot 5 \\
7 \cdot 0 \\
6.9 \\
7 \cdot 3\end{array}$ & $\begin{array}{l}1.5 \\
1.4 \\
1.3 \\
1.1 \\
1.0 \\
1.0 \\
1.1\end{array}$ & $\begin{array}{r}6 \cdot 6 \\
6 \cdot 3 \\
7 \cdot 3 \\
8 \cdot 1 \\
8 \cdot 9 \\
10 \cdot 3 \\
11 \cdot 8\end{array}$ & $\begin{array}{r}4.6 \\
5.1 \\
5.9 \\
6.6 \\
7.2 \\
8.6 \\
10.3\end{array}$ & $\begin{array}{l}1.5 \\
1.2 \\
1.2 \\
1.2 \\
1.2 \\
1.2 \\
1.1\end{array}$ \\
\hline
\end{tabular}

${ }^{2}$ All cancers include ICD-9 140-209

All defined cancers include ICD-9 195-199.1

Table III Regional variation in age adjusted mortality rate $e^{\mathrm{a}}$ for unknown primary cancer, USA, 1984-1988

\begin{tabular}{|c|c|c|c|}
\hline \multirow[b]{2}{*}{ Region } & \multirow[b]{2}{*}{ State } & \multicolumn{2}{|c|}{ Age adjusted rate } \\
\hline & & White & Black \\
\hline West & Washington, Oregon, California & $12 \cdot 5$ & $17 \cdot 1$ \\
\hline Mountain & $\begin{array}{l}\text { Montana, Idaho, Wyoming, Nevada, Utah, } \\
\text { Colorado, Arizona, New Mexico }\end{array}$ & $13 \cdot 3$ & $16 \cdot 8$ \\
\hline West north central & $\begin{array}{l}\text { N. Dakota, S. Dakota, Minnesota, Nebraska, } \\
\text { Iowa, Kansas, Missouri }\end{array}$ & $11 \cdot 7$ & $23 \cdot 3$ \\
\hline West south central & Oklahoma, Texas, Louisiana, Arkansas & $16 \cdot 0$ & $23 \cdot 4$ \\
\hline East north central & Michigan, Wisconsin, Ohio, Illinois, Indiana & $13 \cdot 0$ & $18 \cdot 0$ \\
\hline East south central & Kentucky, Tennessee, Alabama, Mississippi & $14 \cdot 0$ & $22 \cdot 5$ \\
\hline South Atlantic & $\begin{array}{l}\text { Florida, Georgia, North Carolina, South Car- } \\
\text { olina, Virginia, W Virginia, Maryland, District } \\
\text { of Columbia }\end{array}$ & $12 \cdot 9$ & $19 \cdot 3$ \\
\hline Middle Atlantic & Pennsylvania, New York, New Jersey & 13.5 & $18 \cdot 3$ \\
\hline New England & $\begin{array}{l}\text { Maine, New Hampshire, Vermont, Con- } \\
\text { necticut, Rhode Island }\end{array}$ & $15 \cdot 1$ & $19 \cdot 6$ \\
\hline
\end{tabular}

${ }^{a}$ Rates are per 100000 population, age adjusted to the 1980 US Population. relative (black/white) cancer incidence rates were derived and compared to relative (black/white) mortality rates for ill defined cancers. State and regional family income levels were obtained from the 1980 census and compared to corresponding mortality rates.

Confidence intervals $(95 \%)$ of the relative mortality rates were calculated using the method derived by Crow and Gardener. ${ }^{8}$

\section{Results}

During the period 1984 to 1988 an average of 34921 deaths per year in the USA were attributed to ill defined cancers, accounting for $7.4 \%$ of all cancer deaths. Figure 1 depicts the trend in the age adjusted rate between 1979 and 1988. The mortality rate increased $8.7 \%$ between 1979 and 1988 (an average of $1 \%$ per year) and was 13.8 per 100000 population in 1988 .

The mortality rate due to ill defined cancer among black men was $50 \%$ higher than among white men (table I). Similarly, the mortality rate due to ill defined cancer among black women was $40 \%$ higher than among white women. Black men had the highest rate, followed by white men and black women. White women had the lowest rate.

A direct relationship was observed between the mortality rate of ill defined cancers and age during the period 1984 to 1988 . The mortality rate for ill defined cancers increased sharply with age, rising more than ninefold as the age of the decedents rose from 50 to 90 years (data not shown).

The percentage of cancer deaths due to ill defined cancer was higher among blacks than whites (table II). As age increased, the percentage increased from $6.6 \%$ to $11.8 \%$ among black women and $4.6 \%$ to $10.3 \%$ among white women. Among black men, the percentage was higher among those younger than age 54 years $(9.4 \%)$. Among white men, the percentage was similar $(7 \cdot 1 \%)$ across all age groupings.

There was considerable geographical variation in the ill defined cancer mortality rate as well as in the proportion of cancer deaths due to ill defined cancer (table III). Among blacks, for example, the lowest rates were observed in the mountain and western states (17 per 100000 population); the highest rates were clustered in the central region (23 per 100000 population).

The District of Columbia had the highest rate of ill defined cancer mortality (21.7 per 100000 population) when compared to all other states. The rate in DC was $24 \cdot 8$ per 100000 population among blacks and 15.3 per 100000 population among whites. The ill defined cancer mortality rate in DC was $58 \%$ higher than the national rate, while its overall cancer mortality rate exceeded the national rate by $29 \%$. During 1984-1988 in DC, an average of 148 deaths occurred each year due to ill defined cancer, accounting for $9.2 \%$ of all cancer deaths. The relative order of the ill defined cancer mortality rates in the district, delineated by race and sex, was identical to that of the nation (table I).

To determine if the higher mortality of ill defined cancer among blacks was due to their overall higher cancer incidence, mortality rates due to ill defined cancer were compared to incidence rates for all cancers combined (fig 2). 
The relative mortality rate due to ill defined cancer mortality was consistently greater than the relative incidence of all cancers. The effect was most pronounced among younger black men (fig 2A) and women (fig 2B) and diminished with increasing age.

\section{Discussion}

Despite reported progress in the prevention, diagnosis, and treatment of some cancers, ill defined cancer remains the fourth leading site of cancer mortality in the USA, exceeded only by cancers of the lung, colon/rectum, and breast. ${ }^{9-11}$ Among US blacks, ill defined cancer is tied as the third leading site of cancer death with prostate cancer, and is surpassed only by cancers of the lung and colon/rectum. Although the total cancer mortality rate has remained stable since 1980 , the ill defined cancer mortality rate has not declined.

The magnitude of the problem is underestimated by this analysis because other ill defined or unspecified cancer deaths (eg, ICD 159 cancer of the gastrointestinal tract), although relatively few in number $(n=1700 /$ year $)$, have not been included. The large proportion of ill defined cancer cases and deaths has potentially biased the accuracy of national and local cancer incidence and mortality statistics, placing uncertainty in the rates of other cancer sites. ${ }^{1213}$

The higher mortality of ill defined cancer among the black population is not explained by the higher overall cancer incidence among blacks, and suggests the influence of socioeconomic or cultural barriers that affect the use, accessibility, or quality of health care services. Blacks are known to be less likely to have a regular source of health care or health insurance, rely more on emergency rooms and clinics, and have fewer physician encounters than whites $(4.7 v 5.5$ visits per year). ${ }^{14-17}$ Further, blacks are less knowledgeable about the warning signs of cancer and less aware of cancer screening tests than whites. ${ }^{18-}$ ${ }^{20}$ Delay in diagnosis, underutilisation of health services, and substandard health care reflect the influence of poverty that disproportionately affects blacks, but is incurred by socioeconomically disadvantaged people of all races. ${ }^{2122}$

The observed clustering of high rates of ill defined cancer mortality among blacks in the

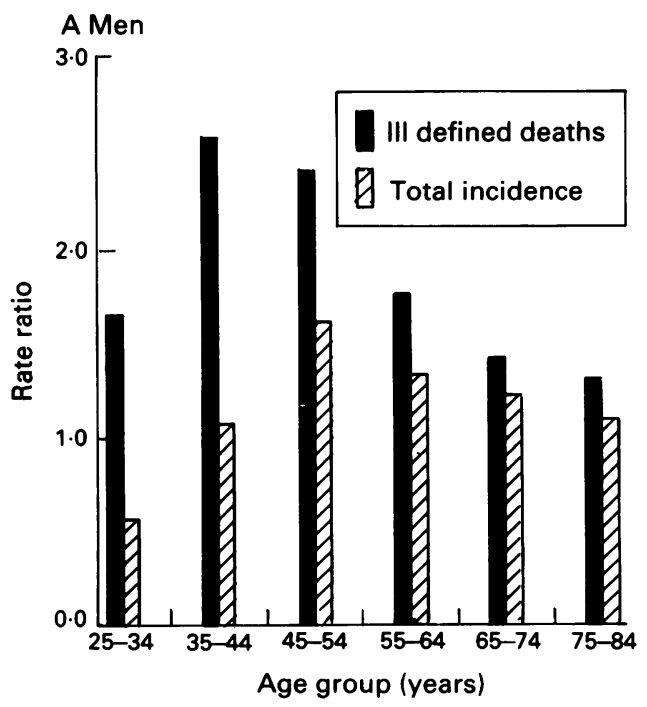

central states (table III) coincides with the concentration of poverty in the midwest and south. ${ }^{4}$ National (US) racial differentials in median family income (black: $\$ 12618$; white: $\$ 20840$ ), educational attainment ( $8 \%$ of blacks completed college compared to $18 \%$ of whites), and unemployment (black: $12 \%$; white: $5.8 \%$ ) reveal the strong correlation of race and socioeconomic status on a population basis. ${ }^{4} \mathrm{~A}$ definitive analysis of the impact of socioeconomic factors on ill defined cancer mortality was precluded in this study because vital records do not provide information regarding each individual decedent's previous income, educational attainment, or medical insurance status.

Other explanations for the observed geographical variability in ill defined cancer mortality rates may include (1) differences in death certification practices that lead to misclassification of the cause of death, (2) variations in the proportion of cancers that present at a late stage, (3) differences in the particular mix of cancer sites in a given population reflecting population composition and exposure to carcinogenic agents, or (4) variations in the use, accessibility, or quality of health care including the thoroughness of diagnostic testing.

The high rate of ill defined cancer mortality observed in the District of Columbia is not fully explained by the high total cancer death rate, and is likely to reflect the large population of medically uninsured $(16 \%)$ and underserved poor $(22 \%$ of the DC black population live below the poverty level). ${ }^{4}$ The magnified problem of poverty and deprivation in DC is reflected in increased rates of other health indicators such as infant mortality (twice the national rate), tuberculosis mortality (five times the national rate), cervical cancer mortality (nearly twice the national rate), and a life expectancy of 4.5 years less than the national average. $^{2324}$

The argument that differences in access to health care can explain the mortality differentials is bolstered by the results of the age specific mortality ratio analysis. The narrowing of the disparity in the mortality rate due to ill defined cancer between blacks and whites among those older than age 65 years (fig 2) is consistent with the more equal access to health care afforded to all elderly Americans through Medicare insurance.

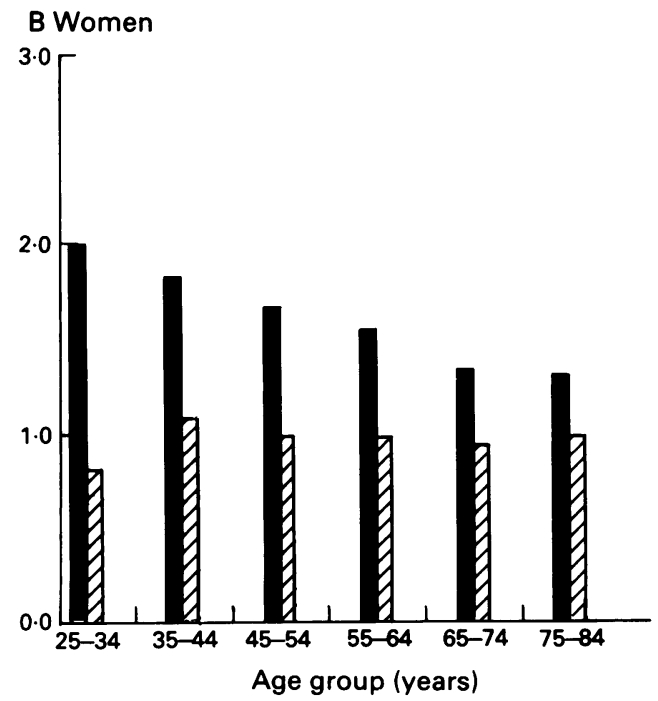

Figure 2 Rate ratios of black to white ill defined cancer mortality and total incidence rates by sex and age, USA, 1984-1987. Ill defined cancers $=I C D$ codes 195-199.1; total cancers
209

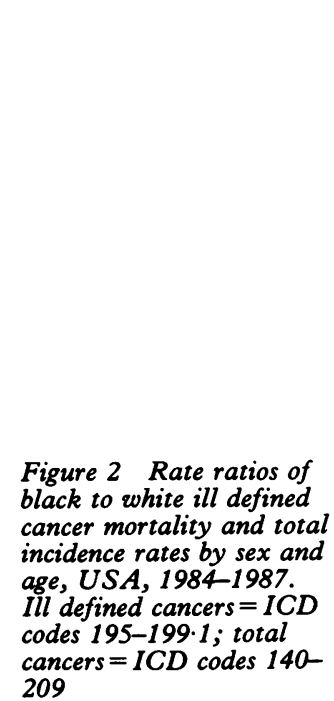


The introduction of new and improved diagnostic techniques (eg, computed tomography, magnetic resonance imaging, colonoscopy, tumour markers, and immunohistological tests) during the past two decades has failed to produce an overall reduction in the ill defined cancer mortality rate. This may reflect limits in the availability, utilisation, or effectiveness of this technology, or alternatively, the increases in the cancer incidence of particular sites or an increasing trend toward late stage presentation may simply have outpaced the impact of advanced technology.

The increasing mortality rate of ill defined cancers during the study period may be an artefact of misclassification of the cause of death, and is consistent with the reported increasing use of non-specific terminology on death records. ${ }^{12} 13$

Although more precise diagnostic information may have been documented in hospital outpatient medical records, this information may have been omitted from death certificates, particularly when certification is made by those not familiar with the decedent's case (eg, following multiple hospital transfers or in emergency rooms). Thus misclassification may also explain some of the racial differential in the mortality rate of ill defined cancer.

Rutstein and colleagues have suggested the use of a set of sentinel causes of death as indicators of potential gaps in the access, timeliness, or quality of health care. ${ }^{25}$ Application of Rutstein's methods in the USA and DC revealed striking racial differences in mortality due to treatable conditions such as cervical cancer, asthma, and tuberculosis. ${ }^{23}$ The similar racial disparity in mortality due to ill defined cancer suggests that it, too, may serve as an indicator of deficiencies in the health care sytem.

We encourage state and local public health officials to monitor the trends in mortality due to ill defined cancers and initiate retrospective case investigations. Investigation of a sample of cases, analogous to infant or maternal mortality case reviews, may identify specific gaps in cancer prevention and control efforts such as public education regarding the early warning signs of cancer or availability of low cost mammography and cervical cancer screening. Further, these inquiries may serve as a surveillance tool to assess the accuracy of death records and measure the equity and quality of the health care sytems in their area.
The authors express their appreciation to Prof John C Bailer III and Dr David Himmelstein for their help in reviewing this manuscript.

1 World Health Organization. International classification of diseases, 9th revision. Geneva: WHO, 1977.

2 Krementz ET, Cerise EJ, Foster DS, Morgan LR. Metastases of undetermined source. Curr Probl Cancer 1979; 4: 1-37.

3 Becker TM, Wiggins CL, Key CR, Samet JM. Symptoms, signs and ill-defined conditions: a leading cause of death signs and ill-defined conditions: a leading cause of deat

4 US Dept of Commerce. Census of the population. General social and economic characteristics-1980. Washington DC Bureau of the Census, 1983.

5 Riggan WB, Van Bruggen J, Acquavella JF, Beaubier J, Mason TJ. US cancer mortality rates and trends, 1950-1979. Washington DC: NCI/EPA, 1983.

6 Government of the District of Columbia. 1986 Provisional population estimates. Washington DC: Office of Planning, Data Services Division, 1987.

7 National Center for Health Statistics. Public access mortality tape, 1969-1988. Hyattsville, Maryland.

8 Crow EL, Gardner RS. Confidence intervals for the expectation of a Poisson variable. Biometrika 1959; 46: 441-7.

9 National Cancer Institute. Cancer control objectives for the nation: 1985-2000. Bethesda, MD: NCI Monographs No 2, 1986.

10 Bailer JC, Smith EM. Progress against cancer? N Engl f Med 1986; 314: 1226-32.

11 National Cancer Institute. Cancer statistics review, 19731987. Bethesda, Maryland: Division of Cancer Prevention and Control, Surveillance Program, 1991.

12 Gittelsohn AM. On the distribution of underlying causes of death. Am ₹ Public Health 1982; 72: 133-40.

13 Percy C, Stanek E, Gloeckler L. Accuracy of cancer death certificates and its effect on cancer mortality statistics. $A m \mathcal{F}$ Public Health 1981; 71: 242-50.

14 Robert Wood Johnson Foundation. Access to health care in the United States: results of a 1986 survey. Princeton, NJ: Special report No 2, 1987.

15 US General Accounting Office. Health insurance coverage: $A$ profile of the uninsured in selected states. Gaithersburg, Maryland: GAO/HRD-91-31FS, 1991.

16 Neighbors HW. Ambulatory medical care among adult black Americans: the hospital emergency room. $7 \mathrm{Natl} \mathrm{Med}$ Assoc 1986; 78: 275-82.

17 US Dept of Health and Human Services. Health of black and white Americans, 1985-1987. National Center for Health white Americans, 1985-1987. National Center for Health Statistics, Series 10: data from the health
No 171. Hyattsville, Maryland, 1990.

18 Denniston RW. Cancer knowledge, attitudes, and practices among black Americans. In Mettlin C, ed. Cancer among black populations. New York: Alan R Liss, 1981.

19 Anonymous. Black Americans' attitudes toward cancer and cancer tests: highlights of a study. $C A$ 1981; 31: 212-8.

20 National Cancer Institute. Technical report-Cancer prevention awareness survey (Wave II). Bethesda, MD: NIH No 87-2907, 1986.

21 Freeman HP. Cancer and the socioeconomically disadvantaged. $C A$ 1990; 39: 263-95.

22 Bergner L, Yerby A. Low income and barriers to use of health services. $N$ Engl f Med 1968; 278: 541-6.

23 Schwartz E, Kofie VY, Rivo M, Tuckson RV. Black/white comparisons of deaths preventable by medical intervention: Comparisons of deaths preventable by medical intervention: United States and the District

J Epidemiol 1990; 19: 591-8.
24 US Dept of Human Services. US decennial life tables for 1979-1981. Vol 2. State life tables, number 9. Hyattsville: National Center for Health Statistics, 1986.

25 Rutstein DD, Berenberg W, Chalmers TC, Child CG, Fishman AP, Perrin EB. Measuring the quality of medical care-a clinical method. $N$ Engl f Med 1976; 294: 582-8. 